\title{
A Significant Statistical Advancement on the Predictive Values of ERCC1 Polymorphisms for Clinical Outcomes of Platinum-Based Chemotherapy in Non-Small Cell Lung Cancer: An Updated Meta-Analysis
}

\author{
Yali Han, ${ }^{1,2}$ Jie Liu, ${ }^{1}$ Meili Sun, ${ }^{1}$ Zongpu Zhang, ${ }^{2}$ Chuanyong Liu, ${ }^{1}$ and Yuping Sun' \\ ${ }^{1}$ Department of Oncology, Jinan Central Hospital, Shandong University, Jinan, Shandong 250013, China \\ ${ }^{2}$ School of Medicine, Shandong University, Jinan, Shandong 250012, China
}

Correspondence should be addressed to Chuanyong Liu; liuchuanyongsdu@163.com

Received 8 May 2015; Accepted 31 August 2015

Academic Editor: Gad Rennert

Copyright (C) 2016 Yali Han et al. This is an open access article distributed under the Creative Commons Attribution License, which permits unrestricted use, distribution, and reproduction in any medium, provided the original work is properly cited.

Background. There is no definitive conclusion so far on the predictive values of ERCC1 polymorphisms for clinical outcomes of platinum-based chemotherapy in non-small cell lung cancer (NSCLC). We updated this meta-analysis with an expectation to obtain some statistical advancement on this issue. Methods. Relevant studies were identified by searching MEDLINE, EMBASE databases from inception to April 2015. Primary outcomes included objective response rate (ORR), progression-free survival (PFS), and overall survival (OS). All analyses were performed using the Review Manager version 5.3 and the Stata version 12.0. Results. A total of 33 studies including 5373 patients were identified. ERCC1 C118T and C8092A could predict both ORR and OS for platinumbased chemotherapy in Asian NSCLC patients (CT + TT versus CC, ORR: OR = 0.80, 95\% CI = 0.67-0.94; OS: $\mathrm{HR}=1.24,95 \% \mathrm{CI}=$ 1.01-1.53) (CA + AA versus CC, ORR: OR =0.76, 95\% CI =0.60-0.96; OS: $\mathrm{HR}=1.37,95 \% \mathrm{CI}=1.06-1.75)$. Conclusions. Current evidence strongly indicated the prospect of ERCC1 C118T and C8092A as predictive biomarkers for platinum-based chemotherapy in Asian NSCLC patients. However, the results should be interpreted with caution and large prospective studies are still required to further investigate these findings.

\section{Introduction}

Lung cancer is currently the most common human malignancies and the leading cause of cancer-related mortality in the world. Non-small cell lung cancer (NSCLC) accounts for $\sim 85 \%$ of all lung cancer cases, with $30 \%$ being squamous cell carcinoma (SCC) and the remaining $(\sim 70 \%)$ being collectively classified as non-SCC [1]. Despite efforts for early detection, approximately two-thirds of NSCLC are diagnosed at advanced stages with limited surgery options. Recent advances in target therapy in NSCLC have added more choices for non-SCC, but chemotherapy still remains the therapeutic mainstay for SCC and some non-SCC. Platinum combined with the third-generation cytotoxic drugs including gemcitabine and pemetrexed is the standard first-line treatment for advanced NSCLC [2].
However, the chemotherapy response and clinical prognosis for NSCLC patients vary remarkably among individuals. Some patients show significant tumor regression while others may develop intrinsic or acquired resistance to chemical drugs, which highlights the need to tailor the treatment for individuals [3]. Pharmacogenomics has been perceived as a useful tool to predict treatment response as well as clinical prognosis in cancer patients, and numerous studies have suggested the functions of single nucleotide polymorphisms (SNPs) in affecting drug sensitivity by modifying relevant genes [4]. Consequently, it is necessary to identify functional gene polymorphisms as new biomarkers for accurately predicting clinical outcomes of chemotherapy in NSCLC, which could also reduce the side effects and provide the most cost-effective approach for individuals [3, $4]$. 
The cytotoxic mechanism of platinum is that the agents bind to DNA and form platinum-DNA adducts, which consequently block DNA replication and transcription, resulting in cellular apoptosis and growth inhibition. The damaged DNA system could be repaired by many biological processes, leading to a resistance to the platinum. The nucleotide excision repair (NER) pathway plays dominant roles in the DNA repair process, which is responsible for the recognition of DNA damage and removal of the damaged nucleotides [5]. Excision repair cross-complementation group 1 (ERCC1) is a key rate-limiting enzyme in the NER pathway. It has been documented that high expression of ERCC1 could block the platinum efficacy and cause drug resistance [6]. Therefore, ERCC1 has become one of the most promising biomarkers for efficacy of platinum-based chemotherapy. Two most common SNPs of ERCC1 gene are C118T (rs11615) with a C $\rightarrow$ T substitution at exon 4 and C8092A (rs3212986) with a $\mathrm{C} \rightarrow$ A change in the $3^{\prime}$-untranslated region, both of which have been speculated to regulate the ERCC1 mRNA expression and manage the NER pathway, consequently affecting the efficacy of platinum-based chemotherapy [7].

To date, lots of studies regarding gene variants that may alter response and tolerability to chemotherapy drugs have been carried out, including both retrospective and perspective studies. The ultimate purpose of a pharmacogenomics analysis is to evaluate the potential value of individual's gene variants to predict the drug efficacy, thus allowing for optimization and personalization of the clinical decision making. However, such an approach seems still a distant goal. The previous results on the relationships between ERCC1 polymorphisms and clinical outcomes of platinumbased chemotherapy in NSCLC are inconclusive and even conflicting to each other, probably due to the complex gene interaction, environmental effects, different detection methods, sample sizes, or study designs. Therefore, we performed a systematic review and meta-analysis of published studies to comprehensively evaluate the predictive values of two promising ERCC1 SNPs for clinical outcomes of platinumbased chemotherapy in NSCLC, with an expectation to provide useful evidence and suggestions for clinical practice and future investigation.

\section{Materials and Methods}

2.1. Literature Search. We searched for original studies investigating the associations between ERCC1 SNPs and platinumbased chemotherapy in NSCLC by using MEDLINE and EMBASE databases. The following terms were combined variously for search: "ERCC1," "platinum or cisplatin or carboplatin," "polymorphism or variant or mutant," and "lung cancer." The literature search was last updated on April 2015. References from retrieved articles and previous meta-analysis were further screened manually for additional qualified studies.

2.2. Inclusion Criteria. The inclusion criteria were as follows: (1) patients should be pathologically confirmed to have NSCLC; (2) studies should assess the relationships between
ERCC1 polymorphisms and clinical outcomes of platinumbased chemotherapy; (3) polymorphisms should be genotyped: ERCC1 C118T (rs11615), C8092A (rs3212986); and (4) clinical outcomes including the objective response rate (ORR), overall survival (OS), and progression-free survival (PFS) should be reported. The most recent and comprehensive data were included if there were duplications.

2.3. Quality Assessment. The quality of each study was assessed independently by two reviewers (Han and Liu) using the Newcastle-Ottawa Scale (NOS), and disputations were settled by a third reviewer (Sun). The NOS consists of 3 parameters for the quality of case-control/cohort study: selection, comparability, and exposure/outcome. Studies with NOS scores $>6$ were considered with high quality [8].

2.4. Data Extraction. Data extraction was performed independently by two investigators (Han and Liu) and disagreements were adjudicated by a third reviewer (Sun). For each study, general characteristics such as the first author, publication year, country and ethnicity of patients, sample size, tumor stages, follow-up time, chemotherapy drugs and treatment line, SNP allele frequency, and genotyping method were collected. Results data included odds ratio (OR) for the ORR, hazard ratios (HR), and 95\% confidence interval (CI) for the OS and PFS. If HR and 95\% CI were not available directly, the estimated value was derived indirectly using Tierney's methods [9].

2.5. Statistic Analysis. The ORR was used to measure the efficacy of chemotherapy regimens. Patients were divided into the responder group including the complete responders (CR) or partial responders (PR) and the nonresponders group including the stable disease (SD) or progressive disease (PD) according to the Response Evaluation Criteria in Solid Tumors criteria [10]. The pooled OR and 95\% CI were calculated by $(\mathrm{CR}+\mathrm{PR}) /(\mathrm{SD}+\mathrm{PD})$. The $\mathrm{OS}$ and PFS on behalf of prognosis of NSCLC patients were evaluated by calculating pooled Cox proportional $\mathrm{HR}$ and 95\% CI as relevant effect measures. The associations between SNPs and ORR/OS/PFS were examined by both the dominant (heterozygote or homozygote variant versus wild type) and codominant models (heterozygote variant versus wild type, homozygote variant versus wild type). Heterogeneity among studies was tested by the Chi-square-based $Q$ test and $I^{2}$ statistics. Values of $P>0.10$ for the $Q$ test or $I^{2}<$ $50 \%$ were considered as lack of heterogeneity and a fixedeffect model was used; otherwise, a random-effect model was used. Subgroup analysis by ethnicity was used to detect and reduce potential source of heterogeneity among studies. The publication bias was investigated by the inverted funnel plot, Begg's test, and Egger's test. Values of $P<0.05$ were indicative of statistically significant publication bias. All $p$ values were two sided. All analyses were performed using the Review Manager version 5.3 (Oxford, England) and the Stata version 12.0 (Stata Corporation, College Station, TX). 


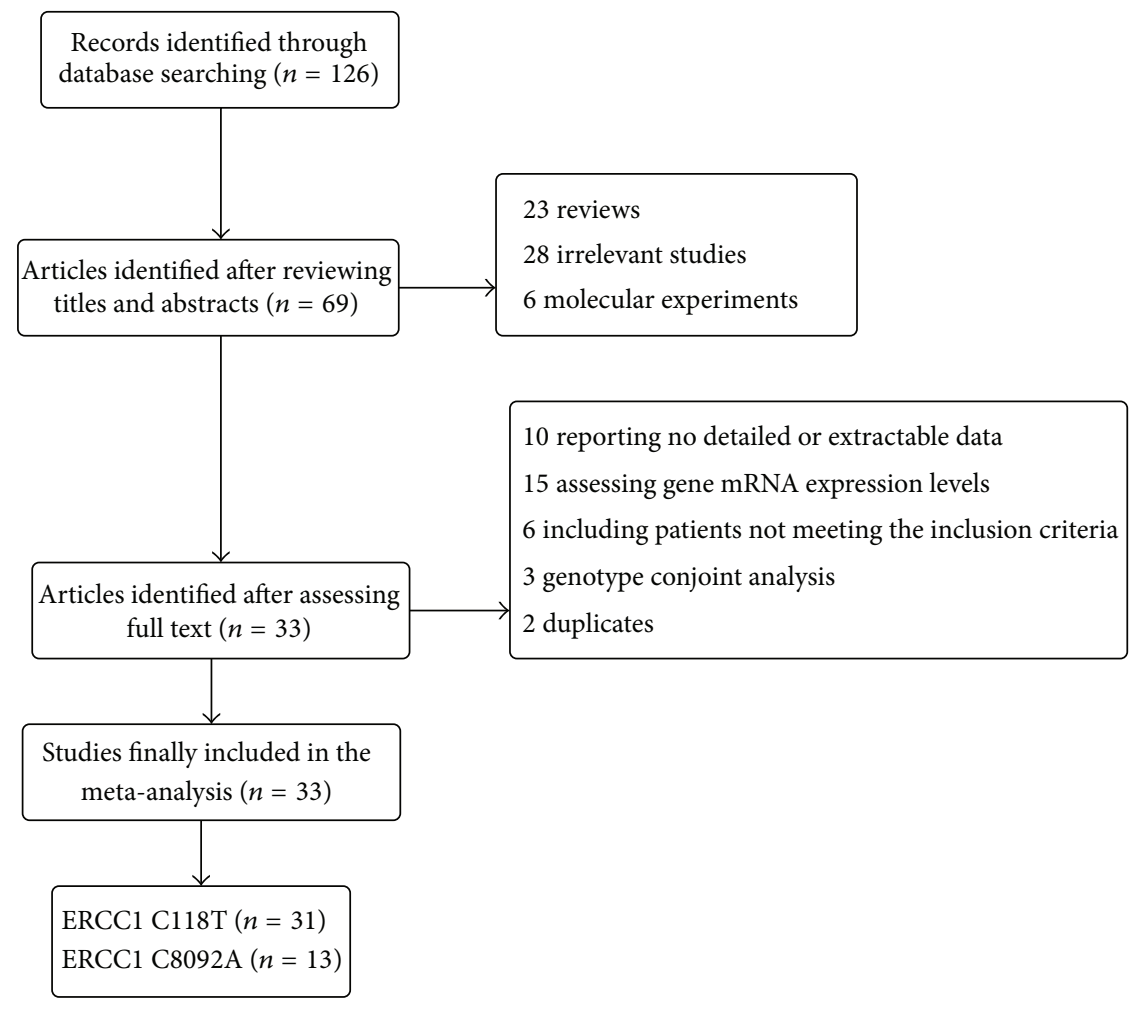

FIGURE 1: Flow chart for the study selection process.

\section{Results}

3.1. Study Identification. As shown in the flow chart for the study selection process (Figure 1), 126 publications were initially retrieved from the PUBMED and EMBASE databases. After screening by checking title and abstract, 57 articles being reviews, meta-analyses, or molecular experiments and other irrelevant studies were excluded. Then, we checked full text for the remaining 69 studies, and subsequently 36 studies were excluded for the following reasons: evaluating the association between gene expression levels and clinical outcome, including patients with SCLC or other tumors, including patients treated with chemotherapy regimens without platinum, conducting the genotype conjoint analysis, and reporting no detailed or extractable survival data. Finally, a total of 33 studies including 5373 patients were identified to be eligible for this meta-analysis. All of our included studies had a high quality with NOS scores $>6$. The baseline characteristics of the included studies were shown in Table 1 and all the results were summarized in Table 2.

\subsection{ERCC1 C118T}

3.2.1. Objective Response Rate. Twenty-three studies including 3272 patients were eligible for this analysis [11-33]. Overall, the $\mathrm{T}$ allele showed a significant association with a poorer ORR (CT + TT versus CC: $\mathrm{OR}=0.82,95 \% \mathrm{CI}=0.71-$ $0.96, I^{2}=48.9 \%$, and $\left.P_{\text {heterogeneity }}=0.005\right)($ Figure $2(\mathrm{a}))$. For the ethnicity-specific subgroup analysis, the $\mathrm{T}$ allele was found to be correlated with a decreased ORR in Asian patients, but not in Caucasian patients (CT + TT versus CC: for Asians, OR =0.80, 95\% CI = 0.67-0.94, $I^{2}=61.9 \%$, and $P_{\text {heterogeneity }}=0.01$; for Caucasians: $\mathrm{OR}=0.93,95 \% \mathrm{CI}=$ $0.66-1.30, I^{2}=5.6 \%$, and $\left.P_{\text {heterogeneity }}=0.389\right)($ Figure $2(\mathrm{a}))$. Similar results were found by the codominant model (CT versus CC: for total, OR $=0.73,95 \% \mathrm{CI}=0.61-0.89, I^{2}=9 \%$, and $P_{\text {heterogeneity }}=0.35$; for Asians, $\mathrm{OR}=0.69,95 \% \mathrm{CI}=0.55-$ $0.85, I^{2}=0 \%$, and $P_{\text {heterogeneity }}=0.44$; for Caucasians, $\mathrm{OR}=$ $0.93,95 \% \mathrm{CI}=0.62-1.38, I^{2}=16 \%$, and $P_{\text {heterogeneity }}=0.31$ ) (TT versus CC: for total, $\mathrm{OR}=0.63,95 \% \mathrm{CI}=0.47-0.85$, $I^{2}=19 \%$, and $P_{\text {heterogeneity }}=0.24$; for Asians, $\mathrm{OR}=0.64$, $95 \%$ CI $=0.44-0.93, I^{2}=20 \%$, and $P_{\text {heterogeneity }}=0.27$; for Caucasians, OR $=0.63,95 \% \mathrm{CI}=0.39-1.01, I^{2}=30 \%$, and $\left.P_{\text {heterogeneity }}=0.20\right)$ (Table 2$)$.

3.2.2. Overall Survival. Seventeen studies including 2926 patients were available for this evaluation $[11,14,15,21,22,25$, 27, 32-41]. Generally, patients with CT or TT genotype had a poorer OS when compared to those with CC genotype (CT + TT versus CC: $\mathrm{HR}=1.25,95 \% \mathrm{CI}=1.05-1.50)$. However, significant heterogeneity $\left(I^{2}=69.2 \%, P_{\text {heterogeneity }}=0.000\right)$ was found in this analysis and the random effect model was applied (Figure 2(b)). In the ethnic subgroup analysis, CT or TT genotype was found to be associated with an unfavorable OS in Asians but not in Caucasians (CT + TT versus CC: for Asians, $\mathrm{HR}=1.24,95 \% \mathrm{CI}=1.01-1.53, I^{2}=79.2 \%$, and $P_{\text {heterogeneity }}=0.000$; for Caucasians, $\mathrm{HR}=1.27,95 \% \mathrm{CI}=$ $0.88-1.85, I^{2}=53.4 \%$, and $\left.P_{\text {heterogeneity }}=0.036\right)($ Figure $2(\mathrm{~b}))$. 


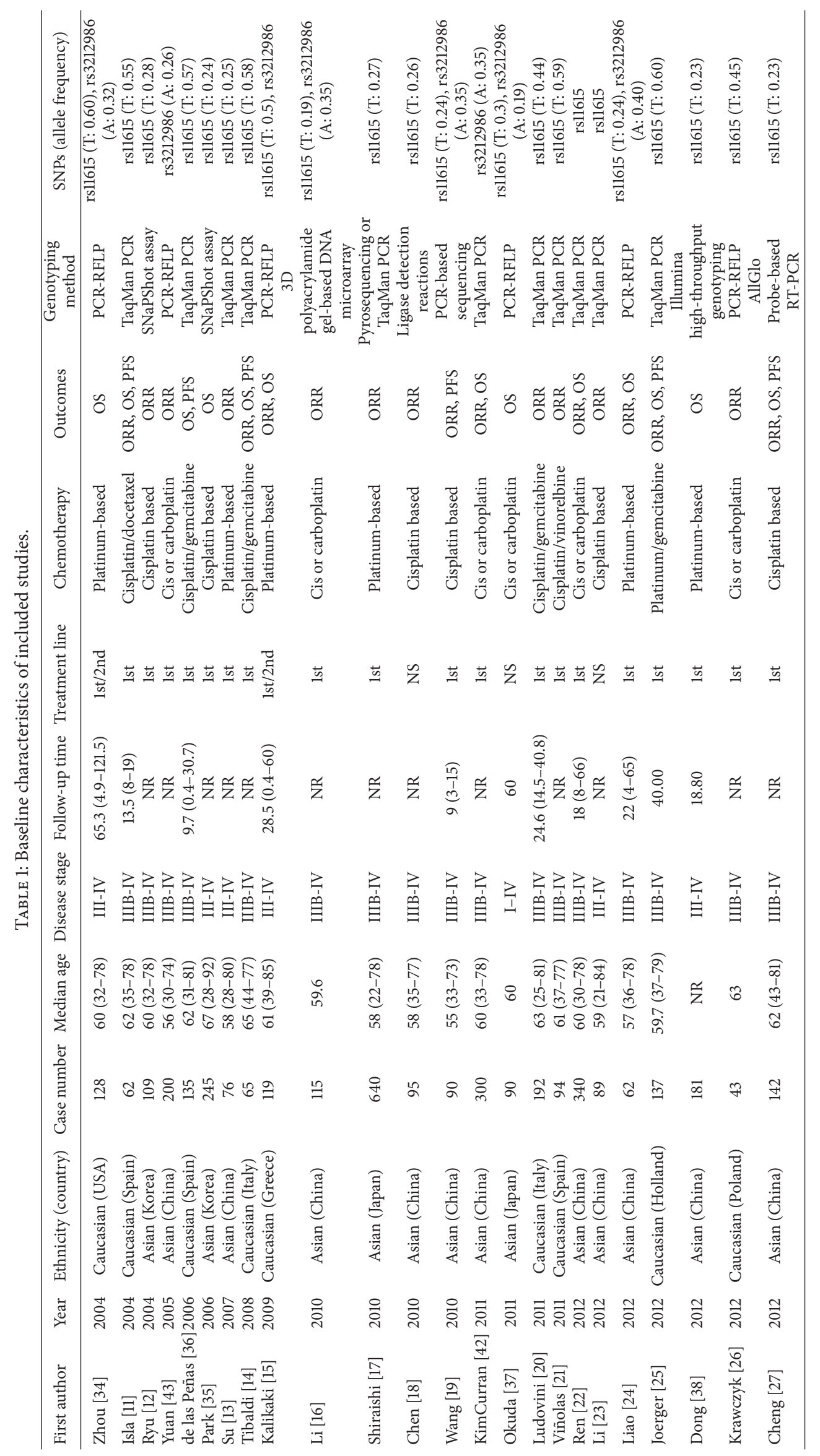




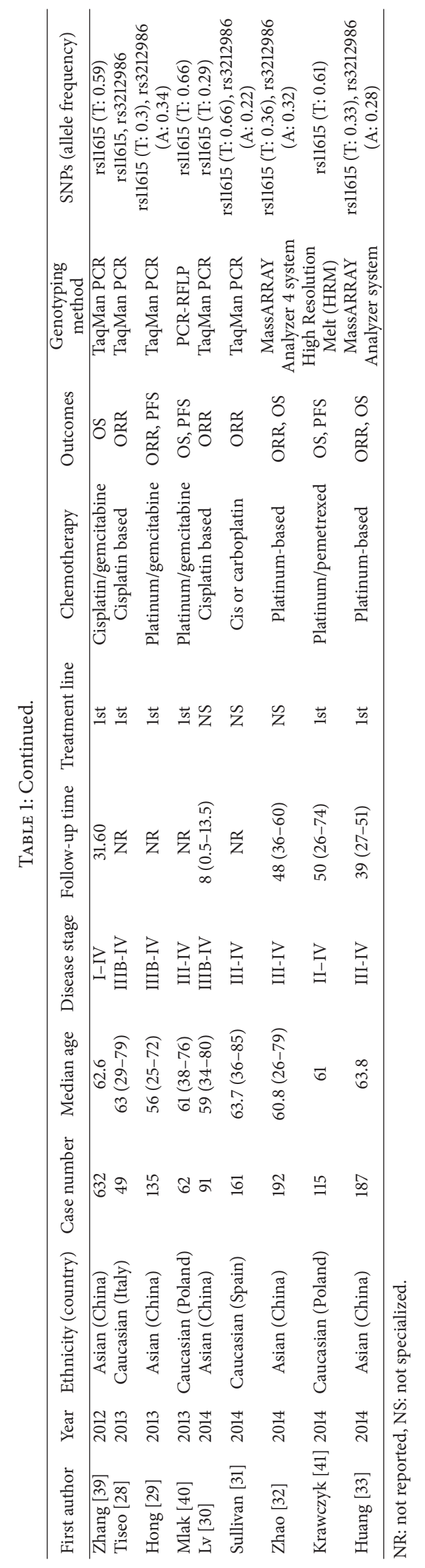




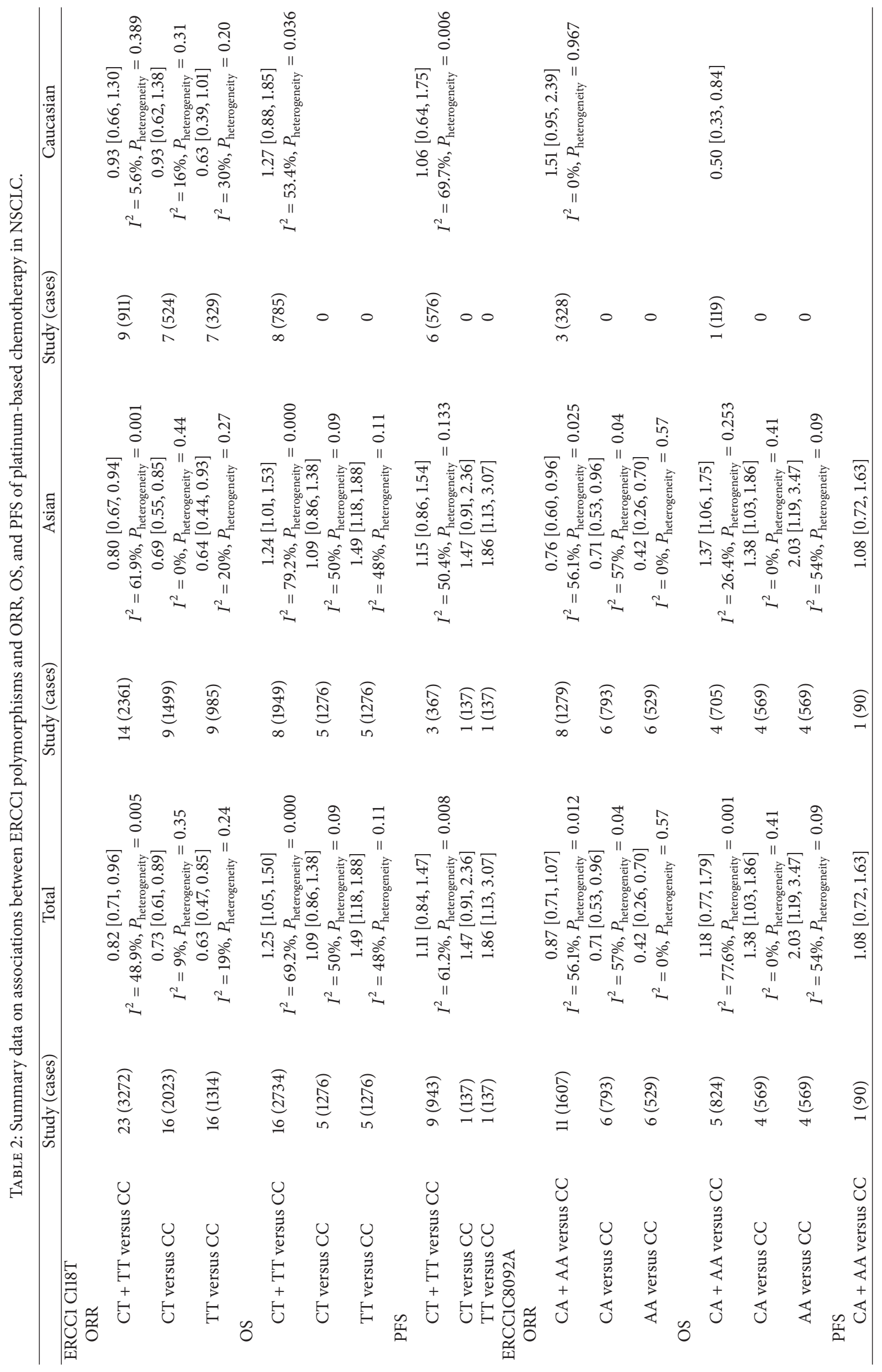




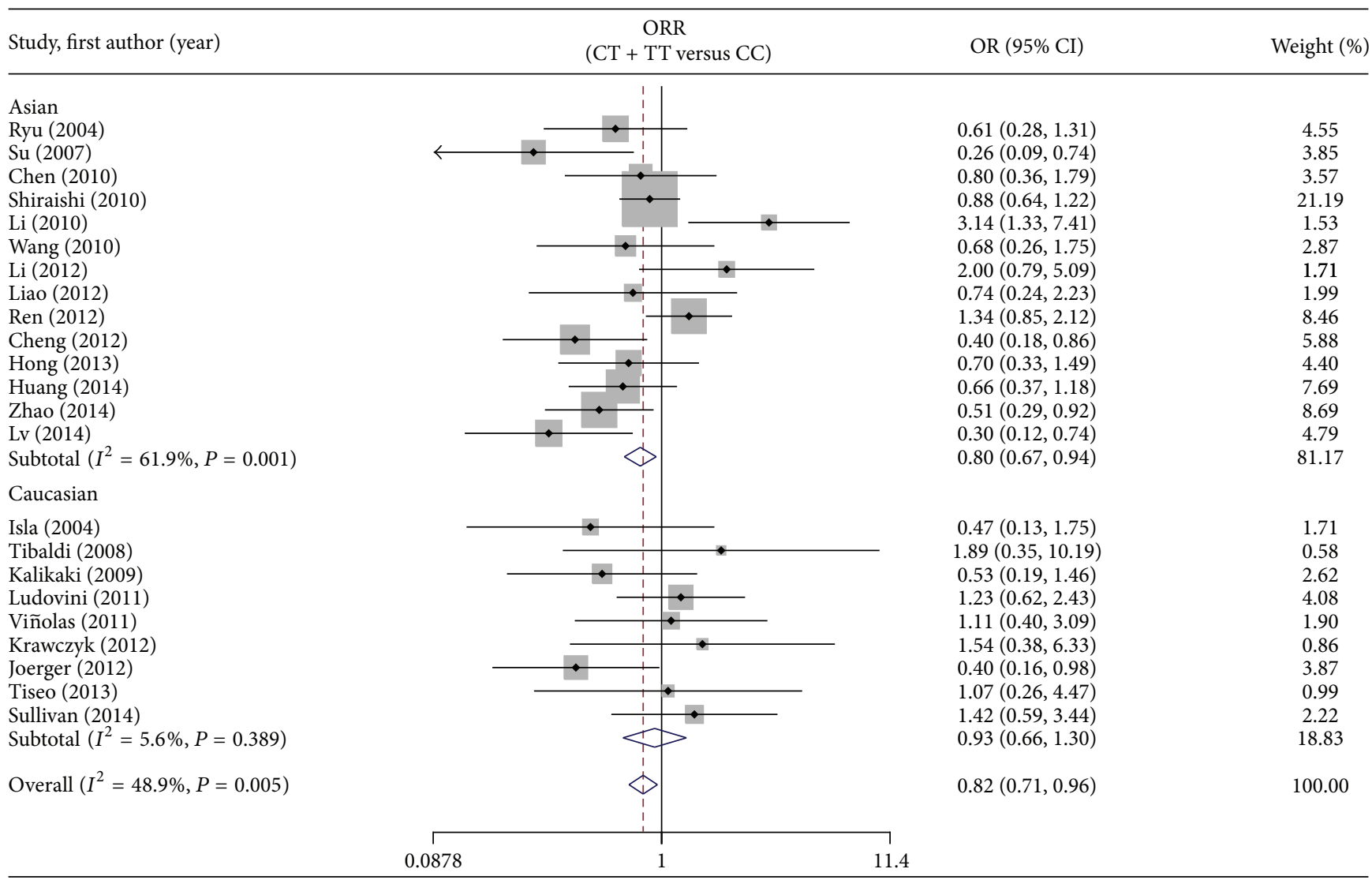

(a)

Study, first author (year)

OS

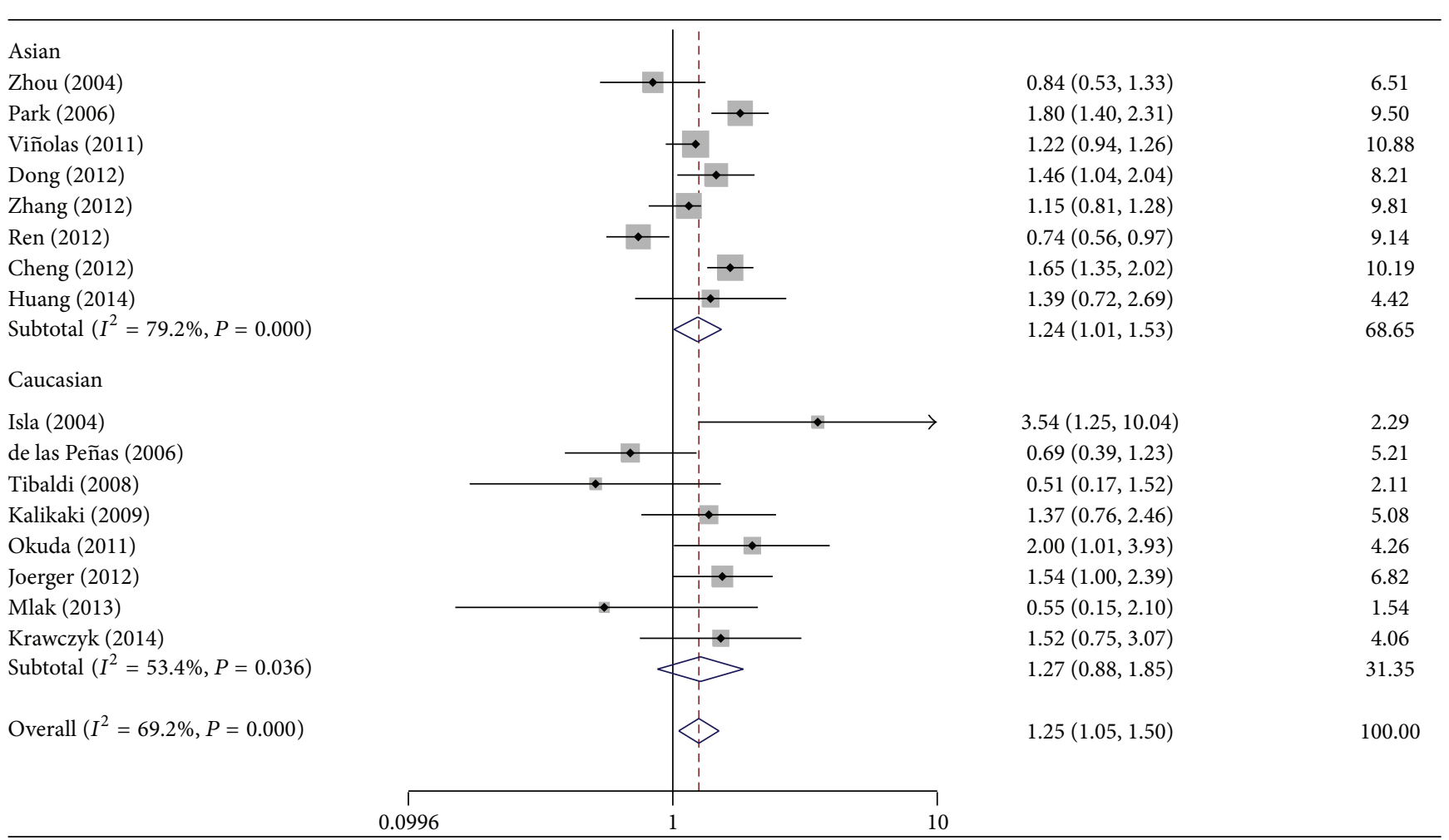

(b)

Figure 2: Continued. 


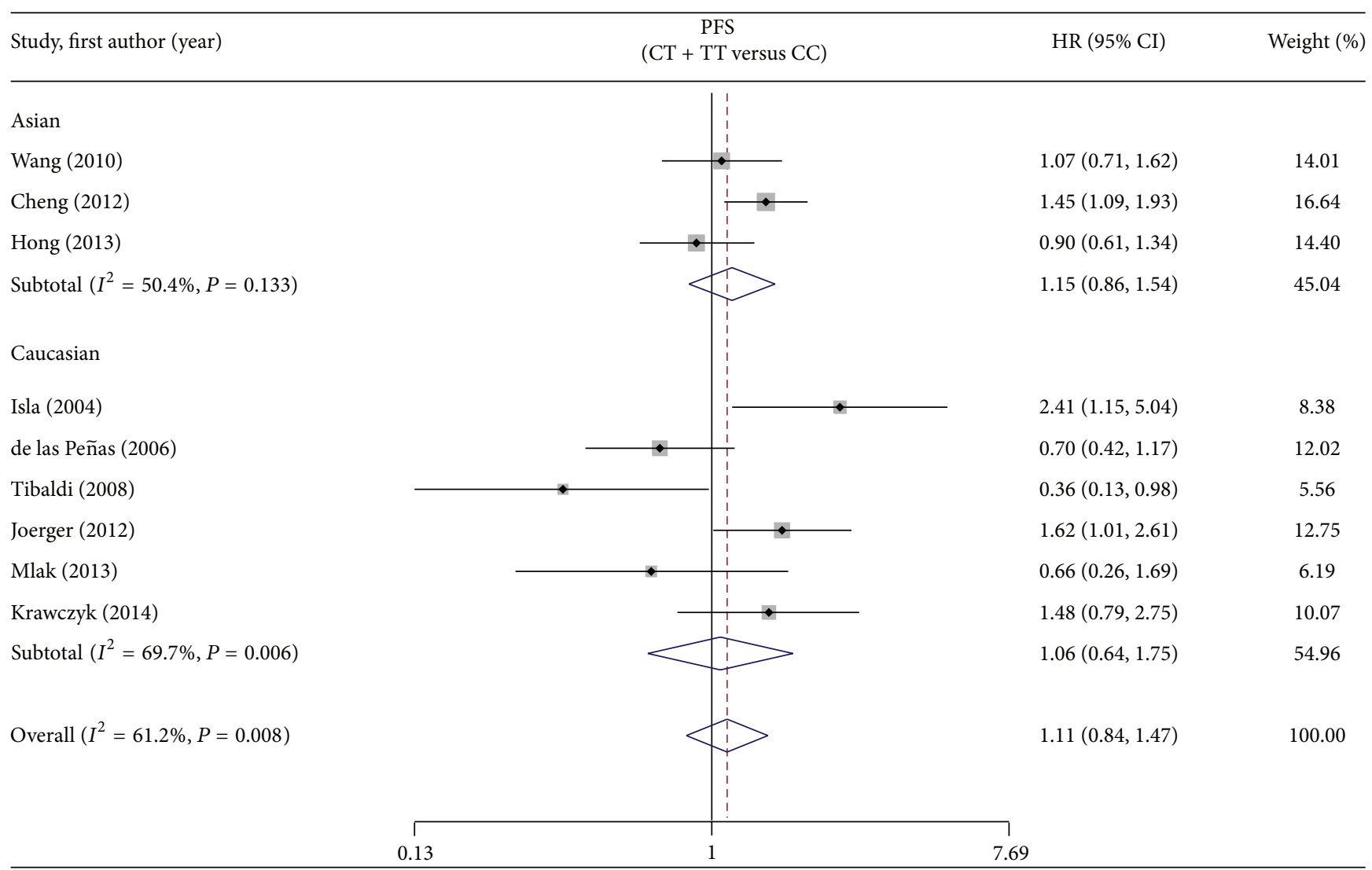

(c)

FIGURE 2: Forest plot of (a) ORR, (b) OS, and (c) PFS in NSCLC patients treated with platinum-based chemotherapy in relation to ERCC1 C118T polymorphism (CT + TT versus CC).

Obvious heterogeneity still existed and sensitivity analysis indicated no study to be deleted. In the codominant model analysis with only Asians, the homozygote showed a more significant trend to be associated with survival than the heterozygote (CT versus CC: $\mathrm{HR}=1.09,95 \% \mathrm{CI}=0.86-1.38$, $I^{2}=50 \%$, and $\left.P_{\text {heterogeneity }}=0.09\right)(\mathrm{TT}$ versus CC: $\mathrm{HR}=$ $1.49,95 \% \mathrm{CI}=1.18-1.88, I^{2}=48 \%$, and $P_{\text {heterogeneity }}=0.11$ ) (Table 2).

3.2.3. Progression-Free Survival. Nine studies with 943 patients were included in this analysis $[11,14,19,25,27,29$, $36,40,41]$. There was no evidence to support an association between the ERCC1 C118T polymorphism and PFS in the dominant model (CT + TT versus CC: $\mathrm{HR}=1.11,95 \% \mathrm{CI}=$ $0.84-1.47, I^{2}=61.2 \%$, and $\left.P_{\text {heterogeneity }}=0.008\right)($ Figure $2(\mathrm{c}))$. The ethnic subgroup analysis also demonstrated no relationship between the ERCC1 C118T polymorphism and PFS in Asians or Caucasians (CT + TT versus CC: for Asians, HR $=1.15,95 \% \mathrm{CI}=0.86-1.54, I^{2}=50.4 \%$, and $P_{\text {heterogeneity }}=$ 0.133; for Caucasians, $\mathrm{HR}=1.06$; $95 \% \mathrm{CI}=0.64-1.75, I^{2}=$ $69.7 \%$, and $P_{\text {heterogeneity }}=0.006$ ) (Figure 2(c)). Only one study conducted this evaluation in the codominant model (CT versus CC: $\mathrm{HR}=1.47,95 \% \mathrm{CI}=0.91-2.36$; $\mathrm{TT}$ versus CC: $\mathrm{HR}=1.86,95 \% \mathrm{CI}=1.13-3.07)$, and the homozygote showed a more obvious trend to be associated with PFS than the heterozygote (Table 2).

\subsection{ERCC1 C8092A}

3.3.1. Objective Response Rate. The data from eleven studies with 1607 patients were included in this evaluation $[15,16,19$, $24,28,29,31-33,42,43]$. In total, no statistically significant association was found between ERCC1 C8092A and ORR $\left(\mathrm{CA}+\mathrm{AA}\right.$ versus CC: $\mathrm{OR}=0.87,95 \% \mathrm{CI}=0.71-1.07, I^{2}=$ $56.1 \%$, and $P_{\text {heterogeneity }}=0.012$ ) (Figure 3(a)). Stratified analysis by ethnicity showed an obvious association in Asians, but not in Caucasians (CA + AA versus CC: for Asians, OR = $0.76,95 \% \mathrm{CI}=0.60-0.96, I^{2}=56.1 \%$, and $P_{\text {heterogeneity }}=$ 0.025; for Caucasians, OR $=1.51,95 \% \mathrm{CI}=0.95-2.39, I^{2}=0 \%$, and $P_{\text {heterogeneity }}=0.967$ ) (Figure $3(\mathrm{a})$ ). Positive results were also found by the codominant model in Asian patients (CA versus $\mathrm{CC}$ : $\mathrm{OR}=0.71,95 \% \mathrm{CI}=0.53-0.96, I^{2}=57 \%$, and $\left.P_{\text {heterogeneity }}=0.04\right)(\mathrm{AA}$ versus CC: $\mathrm{OR}=0.42,95 \% \mathrm{CI}=$ $0.26-0.70, I^{2}=0 \%$, and $\left.P_{\text {heterogeneity }}=0.57\right)($ Table 2$)$.

3.3.2. Overall Survival and Progression-Free Survival. Seven studies consisting of 1078 patients were selected for this analysis $[15,24,32-34,37,42]$. Overall, no correlation was 


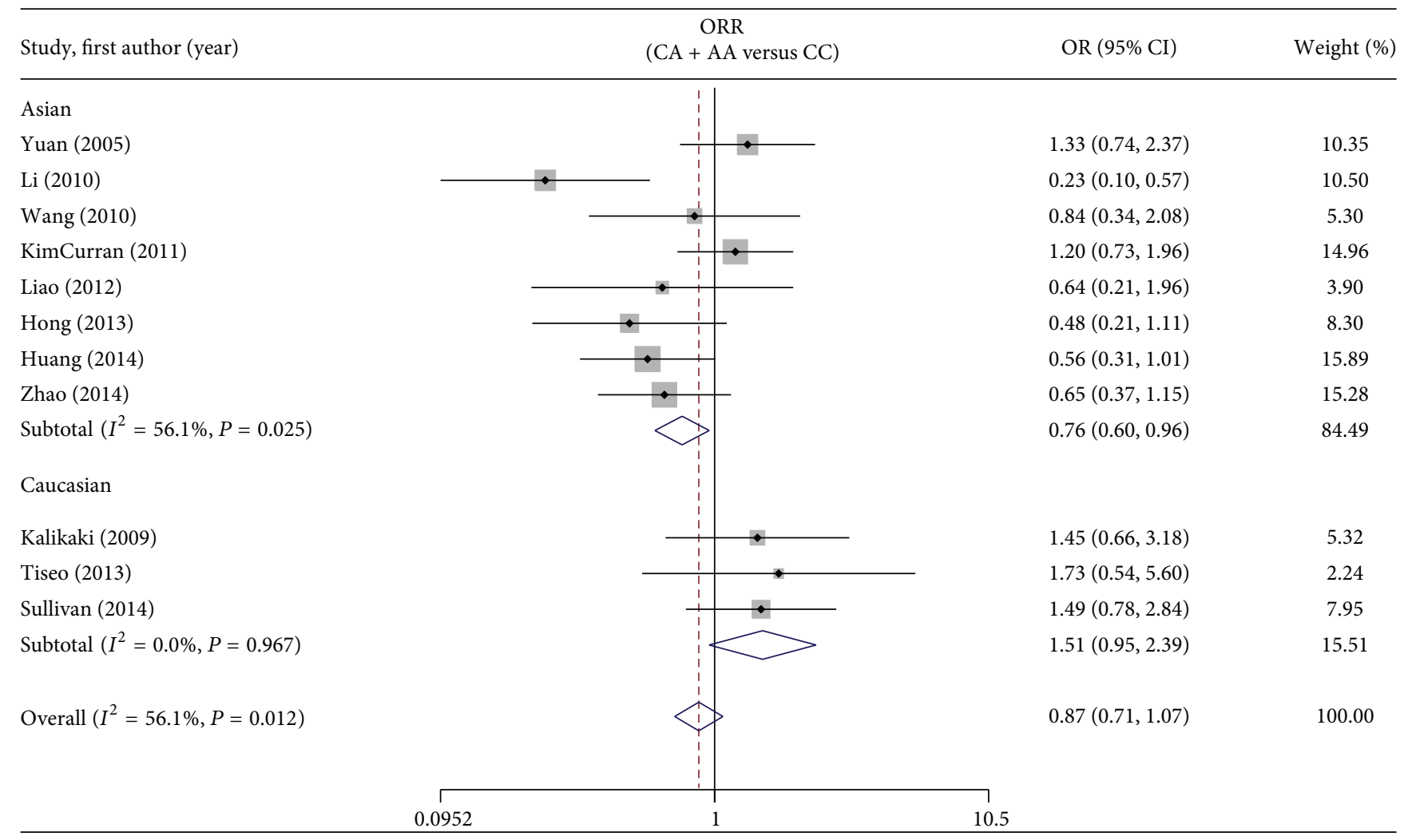

(a)

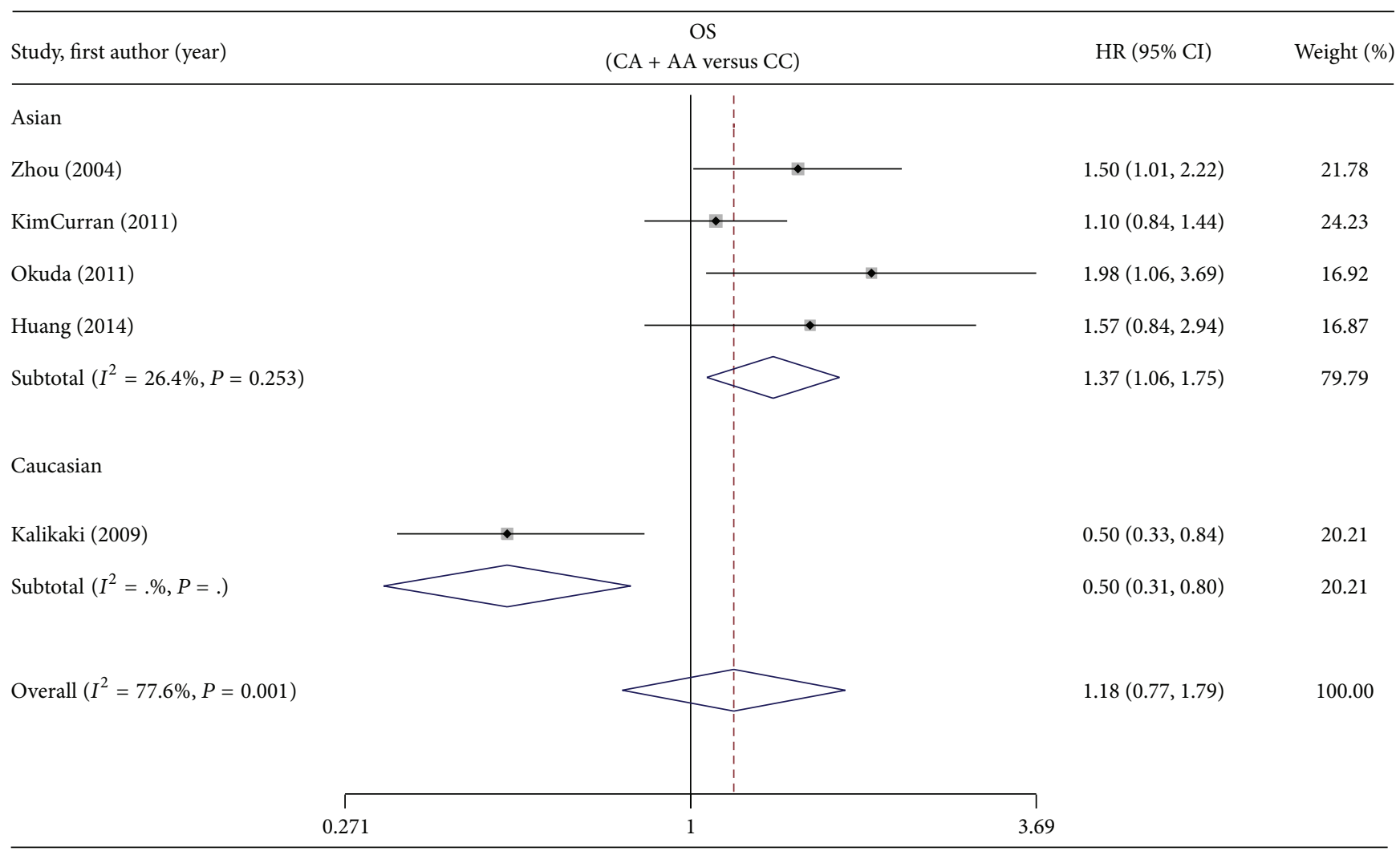

(b)

FIGURE 3: Forest plot of (a) ORR and (b) OS in NSCLC patients treated with platinum-based chemotherapy in relation to ERCC2 C8092A polymorphism (CA + AA versus CC). 
observed between ERCC1 C8092A and survival (CA + AA versus CC: $\mathrm{HR}=1.18,95 \% \mathrm{CI}=0.77-1.79)$, and high level of heterogeneity was also observed in this analysis $\left(I^{2}=\right.$ $77.6 \%, P_{\text {heterogeneity }}=0.001$ ) (Figure 3(b)). After excluding the only one study for Caucasians, A allele was observed to be associated with a worse survival in the remaining four Asian studies ( $\mathrm{HR}=1.37,95 \% \mathrm{CI}=1.06-1.75, I^{2}=26.4 \%$, and $\left.P_{\text {heterogeneity }}=0.253\right)$. Significant association was also found by the codominant model in Asian patients (CA versus CC: $\mathrm{HR}=1.38,95 \% \mathrm{CI}=1.03-1.86, I^{2}=0 \%$, and $P_{\text {heterogeneity }}=$ 0.41 ) (AA versus CC: $\mathrm{HR}=2.03,95 \% \mathrm{CI}=1.19-3.47, I^{2}=$ $54 \%$, and $P_{\text {heterogeneity }}=0.09$ ) (Table 2 ). Only one Chinese study with 90 patients examined the relationship between ERCC1 C8092A and PFS, and no association was observed $(\mathrm{HR}=1.08,95 \% \mathrm{CI}=0.72-1.63)$ (Table 2).

3.4. Publication Bias. The publication bias was performed in the evaluation of the relationship between ERCC1 C118T and ORR by the dominant model, since this comparison included the most studies $(n=23)$. The funnel plot revealed no obvious publication bias, with a symmetrical distribution of study results around the pooled measurement of effect. No evidence of publication bias was detected according to Begg's test $(P=1.000)$ and Egger's test $(P=0.685)$.

\section{Discussion}

The optimal treatment for cancer patients has been evolving for decades. Lots of studies have demonstrated the significant association between gene characteristics and chemotherapy efficacy in individuals. With respect to the gene characteristics, gene polymorphisms are considered more accessible for detection and valuable for evaluation than gene mRNA levels. Single nucleotide polymorphisms (SNPs) have been widely suggested to be capable of affecting the drug sensitivity by modifying functions of relevant genes, thus being predictive biomarkers for treatment efficacy in cancer patients. ERCC1 has been well known to be a promising screening tool in the application of platinum-based chemotherapy in NSCLC. Numerous studies have been carried out to address this question and quite a few meta-analyses evaluating this question have been published. However, to date, no definitive conclusion has been reached yet. The latest meta-analysis was conducted by Yang and Xian who did the literature search to July 31, 2013 [44]. We updated this meta-analysis to evaluate the issue more comprehensively with an expectation to get some statistical advancement. We hope our efforts to select gene biomarkers could make a positive contribution to the progress of optimization and personalization of chemotherapy in NSCLC.

Yang and Xian demonstrated merely a trend of ERCC1 C118T in predicting ORR with no statistical significance (CT + TT versus CC: $\mathrm{OR}=0.94,95 \% \mathrm{CI}=0.72-1.23)$, and stratified analysis by ethnicity also failed to show any valuable results. Besides, they got an opposite trend when analyzing the relevance of C8092A with ORR by the dominant model, probably due to the heterogeneity resulting from ethnicity $(\mathrm{CA}+\mathrm{AA}$ versus CC: for total: $\mathrm{OR}=1.05,95 \% \mathrm{CI}=0.83-1.32$; for Asians: $\mathrm{OR}=0.97,95 \% \mathrm{CI}=0.75-1.25$; for Caucasians: $\mathrm{OR}=1.55,95 \% \mathrm{CI}=0.87-2.74)$. The assessment by the codominant model did not reveal any significant results either. Notably, our updated analysis with more data exactly showed a significant relevance of $\mathrm{T}$ allele and $\mathrm{A}$ allele with a worse ORR compared with $\mathrm{C}$ allele in the Asian subgroup, by both the dominant and codominant models. Our statistically significant results highlight a good prospect of these two ERCC1 SNPs as predictive biomarkers for the response of platinum-based chemotherapy in NSCLC.

Furthermore, when assessing the predictive values of ERCC1 C118T/C8092A for prognosis of NSCLC patients receiving platinum-based chemotherapy, we also obtained some statistical advancements. Yang and Xian observed an association between C118T and OS in totals and in Asians $(\mathrm{CT}+\mathrm{TT}$ versus $\mathrm{CC}$, for total: $\mathrm{HR}=1.26,95 \% \mathrm{CI}=1.02-1.55$, $I^{2}=67 \%$, and $P_{\text {heterogeneity }}<0.001$; for Asians: $\mathrm{HR}=1.35$, $95 \% \mathrm{CI}=1.04-1.75, I^{2}=73.3 \%$, and $P_{\text {heterogeneity }}=0.001$; for Caucasians: $\mathrm{HR}=1.12,95 \% \mathrm{CI}=0.74-1.68, I^{2}=63 \%$, and $P_{\text {heterogeneity }}=0.019$ ), while no apparent correlation between C8092A and OS in both ethnic groups was observed $(\mathrm{CA}+\mathrm{AA}$ versus CC, for total: $\mathrm{HR}=1.26,95 \% \mathrm{CI}=0.81-$ $1.95, I^{2}=87 \%$, and $P_{\text {heterogeneity }}<0.001$; for Asians: $\mathrm{HR}=$ $1.50,95 \% \mathrm{CI}=0.89-2.55, I^{2}=87.4 \%$, and $P_{\text {heterogeneity }}<$ 0.001; for Caucasians: $\mathrm{HR}=0.87,95 \% \mathrm{CI}=0.30-2.56, I^{2}=$ $91.9 \%$, and $\left.P_{\text {heterogeneity }}<0.001\right)$. The great heterogeneity in Yang's analysis to some extent impacted the credibility of their results. Importantly, in our analysis for C8092A, A allele exhibited a significant association with a poorer OS in the Asian subgroup analysis with smaller heterogeneity $(\mathrm{CA}+\mathrm{AA}$ versus CC, for Asians: $\mathrm{HR}=1.37,95 \% \mathrm{CI}=1.06-$ $1.75, I^{2}=26.4 \%$, and $\left.P_{\text {heterogeneity }}=0.253\right)$, and consistent results were observed by the codominant model, which indicated a possibility that C8092A may serve as a predictor for clinical prognosis of platinum-based chemotherapy in NSCLC. Nevertheless, in the C118T analysis, we revealed similar results with Yang's analysis and significant heterogeneity still existed by the dominant model. Notably, in our evaluation by the codominant model which only included Asian patients, the homozygote showed obvious association with an unfavorable OS while the heterozygote only showed a slight trend without statistical significance. This phenomenon presents a possibility that the number of $\mathrm{T}$ alleles may be inversely proportional to the clinical outcome of platinumbased chemotherapy.

Fewer studies reported data of PFS, and most of them performed analysis by the dominant model. Combining the extracted data, we could not identify a predictive role of ERCC1 C118T/C8092A for PFS of platinum-based chemotherapy in NSCLC. However, we also observed a slight trend that the T allele may correlate with a poorer PFS, as the HRs in various comparisons of mutant genotype with wild genotype all showed greater than $1(\mathrm{CT}+\mathrm{TT}$ versus $\mathrm{CC}, \mathrm{HR}=$ 1.11; $\mathrm{CT}$ versus $\mathrm{CC}, \mathrm{HR}=1.47$; and TT versus $\mathrm{CC}, \mathrm{HR}=1.86$ ). Only one study reported the relevance of C8092A with PFS, which also revealed no obvious association. In consideration of the positive results obtained in the evaluation for ORR and OS, there still exists the possibility that minor variants 
in ERCC1 SNPs can as well predict PFS. More studies in the future are expected to confirm this possibility.

In particular consideration of the influence of race on chemosensitivity, we conducted the stratified analysis by ethnicity. Notably, the results revealed a significant distinction between the Asian and the Caucasian subgroups, with ERCC1 SNPs predicting both ORR and OS prominently in Asian patients but not in Caucasian patients. The significant ethnic discrepancy in the predictive roles of ERCC1 SNPs may be due to the gene-gene and gene-environment interactions, different genetic background, and lifestyle, which is not yet clearly defined.

Our work has several strengths. First, we comprehensively evaluated gene effects on the standard first-line treatment in NSCLC, platinum-based chemotherapy, and the indicators covered both treatment efficacy and clinical prognosis (ORR, OS, and PFS); second, we made a statistical progress when evaluating the predictive values of ERCC1 polymorphisms for platinum-based chemotherapy in NSCLC; third, all of our included studies were of high quality and no evident publication bias was observed. All these points significantly increased the statistical power of our analysis.

Despite the strengths of our work, some limitations should be taken into consideration. Above all, an obvious heterogeneity was observed in the analysis of the ERCC1 C118T for OS and PFS and still existed after stratified analysis by ethnicity. It is speculated that the heterogeneity mainly derived from heterogeneous samples and various clinical trial designs: firstly, the baseline characteristics of populations in different trials were impossible to coincide with each other, such as age, sex, histology type, and tumor stage; secondly, clinical trial designs varied in many aspects, such as the coadministration of other drugs, drug administration mode, treatment cycle, treatment line with or without surgery or radiotherapy, and genotyping method. Most of the included studies employed the platinum-based chemotherapy as a first-line treatment; only a few studies did not specialize the treatment line. And the concurrent drugs combined in the platinum-based regimen also to some extent affected the clinical outcome, as the efficacy of gemcitabin and pemetrexed also varied among individuals and could be influenced by certain gene polymorphisms as well, such as ribonucleotide reductase M1(RRM1) and thymidylate synthase (TS). All of these potential discrepancies interfere with the standardization of data acquisition; however, we were unable to conduct a further stratified analysis since most studies did not provide detailed information about these factors. In addition, there inevitably existed some inaccuracies in our data extraction and analysis: firstly, some researches in the literature did not report concrete time-to-event data so that we had to obtain calculable data indirectly by reading Kaplan-Meier curves or conducting data transformation; secondly, most studies reported unadjusted estimates and only a few studies are supplied with adjusted estimates; moreover, those estimates were not always adjusted for the same potential confounders.

We still have a long way to go to ultimately turn to ERCC1 polymorphisms for our clinical decision making, since various factors contribute to the individual variation in drug response. Polymorphism of genes encoding proteins involved in the transport, metabolism, and action of drugs influences the clinical outcome of chemotherapies prominently, and other factors such as age, sex, physical condition, hepatic and renal function, tolerance to toxicity, and alcohol and tobacco use also affect the drug efficacy. All the factors should be taken into account comprehensively when making clinical decisions. Although it is a distant goal, our work has made an important step along this path, indicating a necessity to conduct future prospective studies with large sample sizes and better study designs to validate these conclusions and prove the feasibility of the customization approach to our clinical decision making.

\section{Conclusion}

In conclusion, the prospect of optimal chemotherapy in NSCLC based on validated biomarkers was further confirmed with the latest data. We provided statistical evidence that both ERCC1 C118T and C8092A could be useful predictive biomarkers for platinum-based chemotherapy in Asian NSCLC patients. However, considering the limitations, heterogeneity and biases existed within our analysis, our conclusions should be interpreted with caution, and large prospective studies are still required to further validate these findings.

\section{Conflict of Interests}

The authors declare that there is no conflict of interests regarding the publication of this paper.

\section{Acknowledgment}

This work was supported by grants from the National Natural Science Foundation of China (81372334).

\section{References}

[1] R. L. Siegel, K. D. Miller, and A. Jemal, "Cancer statistics, 2015," CA-A Cancer Journal for Clinicians, vol. 65, no. 1, pp. 5-29, 2015.

[2] D. S. Ettinger, A. K. P. Ganti, R. Govindan et al., "Non-small cell lung cancer," Journal of the National Comprehensive Cancer Network, vol. 8, no. 7, pp. 740-801, 2010.

[3] S. Postel-Vinay, E. Vanhecke, K. A. Olaussen, C. J. Lord, A. Ashworth, and J.-C. Soria, "The potential of exploiting DNArepair defects for optimizing lung cancer treatment," Nature Reviews Clinical Oncology, vol. 9, no. 3, pp. 144-155, 2012.

[4] C. D’Antonio, A. Milano, R. Righini et al., "Pharmacogenomics in lung cancer chemotherapy: a review of what the oncologist should know," Anticancer Research, vol. 34, no. 10, pp. 52415250, 2014.

[5] L. P. Martin, T. C. Hamilton, and R. J. Schilder, "Platinum resistance: the role of DNA repair pathways," Clinical Cancer Research, vol. 14, no. 5, pp. 1291-1295, 2008.

[6] R. Altaha, X. Liang, J. J. Yu, and E. Reed, "Excision repair cross complementing-group 1: gene expression and platinum resistance," International Journal of Molecular Medicine, vol. 14, no. 6, pp. 959-970, 2004. 
[7] T. Furuta, T. Ueda, G. Aune, A. Sarasin, K. H. Kraemer, and Y. Pommier, "Transcription-coupled nucleotide excision repair as a determinant of cisplatin sensitivity of human cells," Cancer Research, vol. 62, no. 17, pp. 4899-4902, 2002.

[8] A. Stang, "Critical evaluation of the Newcastle-Ottawa scale for the assessment of the quality of nonrandomized studies in metaanalyses," European Journal of Epidemiology, vol. 25, no. 9, pp. 603-605, 2010

[9] J. F. Tierney, L. A. Stewart, D. Ghersi, S. Burdett, and M. R. Sydes, "Practical methods for incorporating summary time-toevent data into meta-analysis," Trials, vol. 8, no. 1, article 16, 2007.

[10] P. Therasse, S. G. Arbuck, E. A. Eisenhauer et al., "New guidelines to evaluate the response to treatment in solid tumors," Journal of the National Cancer Institute, vol. 92, no. 3, pp. 205216, 2000.

[11] D. Isla, C. Sarries, R. Rosell et al., "Single nucleotide polymorphisms and outcome in docetaxel-cisplatin-treated advanced non-small-cell lung cancer," Annals of Oncology, vol. 15, no. 8, pp. 1194-1203, 2004.

[12] J.-S. Ryu, Y.-C. Hong, H.-S. Han et al., "Association between polymorphisms of ERCC1 and XPD and survival in non-smallcell lung cancer patients treated with cisplatin combination chemotherapy," Lung Cancer, vol. 44, no. 3, pp. 311-316, 2004.

[13] D. Su, S. Ma, P. Liu et al., "Genetic polymorphisms and treatment response in advanced non-small cell lung cancer," Lung Cancer, vol. 56, no. 2, pp. 281-288, 2007.

[14] C. Tibaldi, E. Giovannetti, E. Vasile et al., "Correlation of CDA, $E R C C 1$, and XPD polymorphisms with response and survival in gemcitabine/cisplatin-treated advanced non-small cell lung cancer patients," Clinical Cancer Research, vol. 14, no. 6, pp. 1797-1803, 2008.

[15] A. Kalikaki, M. Kanaki, H. Vassalou et al., "DNA repair gene polymorphisms predict favorable clinical outcome in advanced non-small-cell lung cancer," Clinical Lung Cancer, vol. 10, no. 2, pp. 118-123, 2009.

[16] F. Li, X. Sun, N. Sun et al., "Association between polymorphisms of ERCC1 and XPD and clinical response to platinum-based chemotherapy in advanced non-small cell lung cancer," American Journal of Clinical Oncology, vol. 33, no. 5, pp. 489-494, 2010.

[17] K. Shiraishi, T. Kohno, C. Tanai et al., "Association of DNA repair gene polymorphisms with response to platinum-based doublet chemotherapy in patients with non-small-cell lung cancer," Journal of Clinical Oncology, vol. 28, no. 33, pp. 49454952, 2010.

[18] S. Chen, X. Huo, Y. Lin et al., "Association of MDR1 and ERCC1 polymorphisms with response and toxicity to cisplatinbased chemotherapy in non-small-cell lung cancer patients," International Journal of Hygiene and Environmental Health, vol. 213, no. 2, pp. 140-145, 2010.

[19] J. Wang, Q. Zhang, H. Zhang et al., "Association between polymorphisms of ERCC1 and response in patients with advanced non-small cell lung cancer receiving cisplatin-based chemotherapy," Chinese Journal of Lung Cancer, vol. 13, no. 4, pp. 337-341, 2010.

[20] V. Ludovini, I. Floriani, L. Pistola et al., "Association of cytidine deaminase and xeroderma pigmentosum group $\mathrm{D}$ polymorphisms with response, toxicity, and survival in cisplatin/gemcitabine-treated advanced non-small cell lung cancer patients," Journal of Thoracic Oncology, vol. 6, no. 12, pp. 2018-2026, 2011.
[21] N. Viñolas, M. Provencio, N. Reguart et al., "Single nucleotide polymorphisms in MDR1 gen correlates with outcome in advanced non-small-cell lung cancer patients treated with cisplatin plus vinorelbine," Lung Cancer, vol. 71, no. 2, pp. 191198, 2011.

[22] S. Ren, S. Zhou, F. Wu et al., "Association between polymorphisms of DNA repair genes and survival of advanced NSCLC patients treated with platinum-based chemotherapy," Lung Cancer, vol. 75, no. 1, pp. 102-109, 2012.

[23] D. Li, Q. Zhou, Y. Liu, Y. Yang, and Q. Li, "DNA repair gene polymorphism associated with sensitivity of lung cancer to therapy," Medical Oncology, vol. 29, no. 3, pp. 1622-1628, 2012.

[24] W.-Y. Liao, J.-Y. Shih, G.-C. Chang et al., "Genetic polymorphism of XRCC1 Arg399Gln is associated with survival in non-small-cell lung cancer patients treated with gemcitabine/platinum," Journal of Thoracic Oncology, vol. 7, no. 6, pp. 973-981, 2012.

[25] M. Joerger, S. A. Burgers, P. Baas et al., "Germline polymorphisms in patients with advanced nonsmall cell lung cancer receiving first-line platinum-gemcitabine chemotherapy: a prospective clinical study," Cancer, vol. 118, no. 9, pp. 2466-2475, 2012.

[26] P. Krawczyk, K. Wojas-Krawczyk, R. Mlak, T. Kucharczyk, B. Biernacka, and J. Milanowski, "Predictive value of ERCC1 single-nucleotide polymorphism in patients receiving platinumbased chemotherapy for locally-advanced and advanced nonsmall cell lung cancer-a pilot study," Folia Histochemica et Cytobiologica, vol. 50, no. 1, pp. 80-86, 2012.

[27] J. Cheng, M. Ha, Y. Wang et al., "A C118T polymorphism of ERCC1 and response to cisplatin chemotherapy in patients with late-stage non-small cell lung cancer," Journal of Cancer Research and Clinical Oncology, vol. 138, no. 2, pp. 231-238, 2012.

[28] M. Tiseo, P. Bordi, B. Bortesi et al., "ERCC1/BRCA1 expression and gene polymorphisms as prognostic and predictive factors in advanced NSCLC treated with or without cisplatin," British Journal of Cancer, vol. 108, no. 8, pp. 1695-1703, 2013.

[29] W. Hong, K. Wang, Y.-P. Zhang et al., "Methylenetetrahydrofolate reductase $\mathrm{C} 677 \mathrm{~T}$ polymorphism predicts response and time to progression to gemcitabine-based chemotherapy for advanced non-small cell lung cancer in a Chinese Han population," Journal of Zhejiang University: Science B, vol. 14, no. 3, pp. 207-215, 2013.

[30] H. Lv, T. Han, X. Shi et al., "Genetic polymorphism of GSTP1 and ERCC1 correlated with response to platinum-based chemotherapy in non-small cell lung cancer," Medical Oncology, vol. 31, no. 8, article 86, 2014.

[31] I. Sullivan, J. Salazar, M. Majem et al., "Pharmacogenetics of the DNA repair pathways in advanced non-small cell lung cancer patients treated with platinum-based chemotherapy," Cancer letters, vol. 353, no. 2, pp. 160-166, 2014.

[32] X. Zhao, Z. Zhang, Y. Yuan, and X. Yuan, "Polymorphisms in ERCC1 gene could predict clinical outcome of platinum-based chemotherapy for non-small cell lung cancer patients," Tumor Biology, vol. 35, no. 8, pp. 8335-8341, 2014.

[33] S.-J. Huang, Y.-F. Wang, Z.-Y. Jin, J.-Y. Sun, and Z.-L. Guo, "Role of ERCC1 variants in response to chemotherapy and clinical outcome of advanced non-small cell lung cancer," Tumor Biology, vol. 35, no. 5, pp. 4023-4029, 2014.

[34] W. Zhou, S. Gurubhagavatula, G. Liu et al., "Excision repair cross-complementation group 1 polymorphism predicts overall survival in advanced non-small cell lung cancer patients treated 
with platinum-based chemotherapy," Clinical Cancer Research, vol. 10, no. 15, pp. 4939-4943, 2004.

[35] S.-Y. Park, Y.-C. Hong, J.-H. Kim et al., "Effect of ERCC1 polymorphisms and the modification by smoking on the survival of non-small cell lung cancer patients," Medical Oncology, vol. 23, no. 4, pp. 489-498, 2006.

[36] R. de las Peñas, M. Sanchez-Ronco, V. Alberola et al., "Polymorphisms in DNA repair genes modulate survival in cisplatin/gemcitabine-treated non-small-cell lung cancer patients," Annals of Oncology, vol. 17, no. 4, pp. 668-675, 2006.

[37] K. Okuda, H. Sasaki, Y. Hikosaka et al., "Excision repair cross complementation group 1 polymorphisms predict overall survival after platinum-based chemotherapy for completely resected non-small-cell lung cancer," Journal of Surgical Research, vol. 168, no. 2, pp. 206-212, 2011.

[38] J. Dong, Z. Hu, Y. Shu et al., "Potentially functional polymorphisms in DNA repair genes and non-small-cell lung cancer survival: a pathway-based analysis," Molecular Carcinogenesis, vol. 51, no. 7, pp. 546-552, 2012.

[39] Z.-Y. Zhang, X. Tian, R. Wu, Y. Liang, and X.-Y. Jin, "Predictive role of ERCC1 and XPD genetic polymorphisms in survival of Chinese non-small cell lung cancer patients receiving chemotherapy," Asian Pacific Journal of Cancer Prevention, vol. 13, no. 6, pp. 2583-2586, 2012.

[40] R. Mlak, P. Krawczyk, R. Ramlau et al., "Predictive value of ERCC1 and RRM1 gene single-nucleotide polymorphisms for first-line platinum- and gemcitabine-based chemotherapy in non-small cell lung cancer patients," Oncology Reports, vol. 30, no. 5, pp. 2385-2398, 2013.

[41] P. Krawczyk, T. Kucharczyk, D. M. Kowalski et al., "Polymorphisms in TS, MTHFR and ERCC1 genes as predictive markers in first-line platinum and pemetrexed therapy in NSCLC patients," Journal of Cancer Research and Clinical Oncology, vol. 140, no. 12, pp. 2047-2057, 2014.

[42] V. Kimcurran, C. Zhou, G. Schmid-Bindert et al., "Lack of correlation between ERCC1 (C8092A) single nucleotide polymorphism and efficacy/toxicity of platinum based chemotherapy in Chinese patients with advanced non-small cell lung cancer," Advances in Medical Sciences, vol. 56, no. 1, pp. 30-38, 2011.

[43] P. Yuan, X.-P. Miao, X.-M. Zhang et al., "Correlation of genetic polymorphisms in nucleotide excision repair system to sensitivity of advanced non-small cell lung cancer patients to platinumbased chemotherapy," Ai Zheng, vol. 24, no. 12, pp. 1510-1513, 2005.

[44] Y. Yang and L. Xian, "The association between the ERCC1/2 polymorphisms and the clinical outcomes of the platinumbased chemotherapy in non-small cell lung cancer (NSCLC): a systematic review and meta-analysis," Tumor Biology, vol. 35, no. 4, pp. 2905-2921, 2014. 


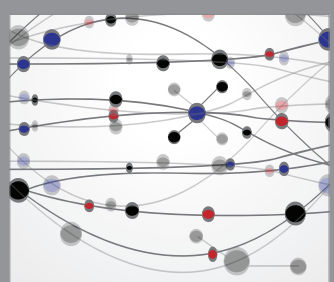

The Scientific World Journal
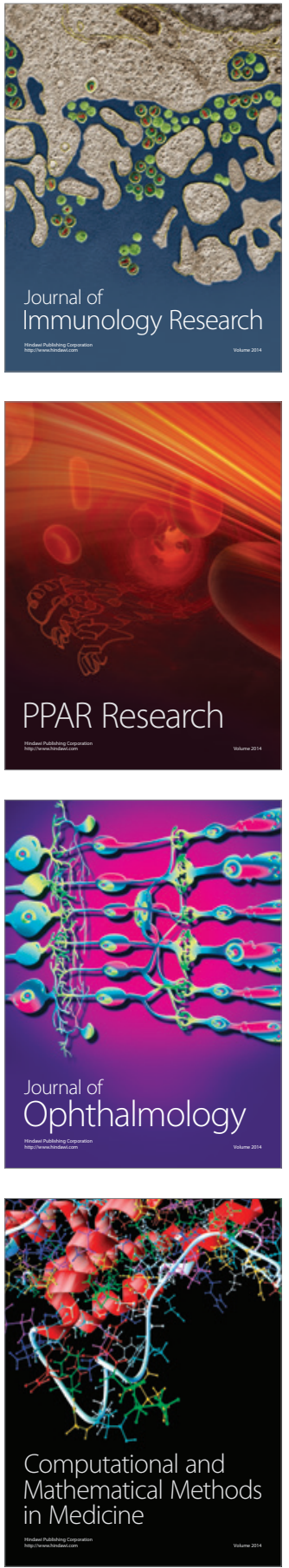

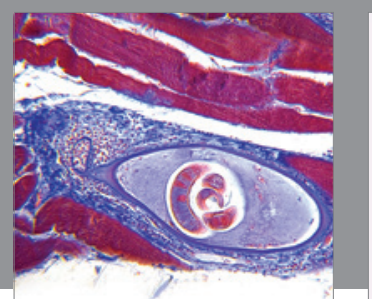

Gastroenterology Research and Practice

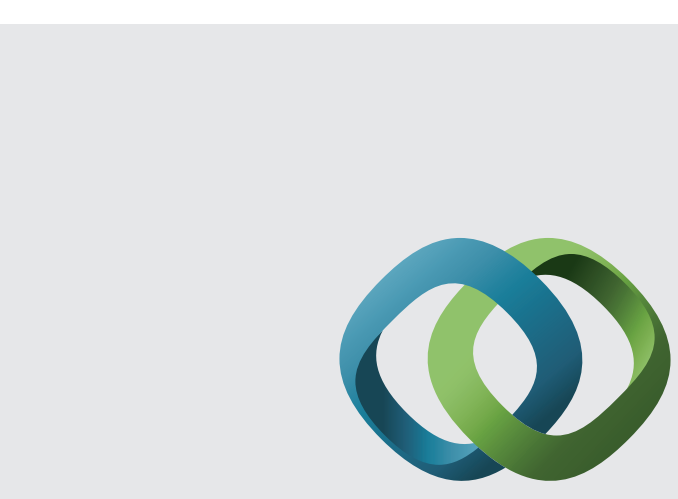

\section{Hindawi}

Submit your manuscripts at

http://www.hindawi.com
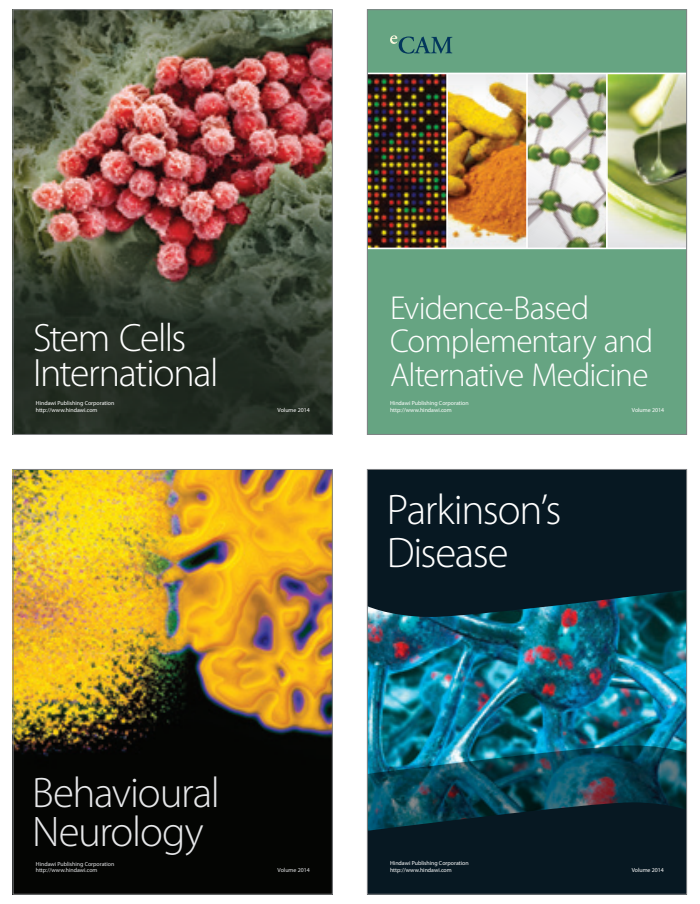
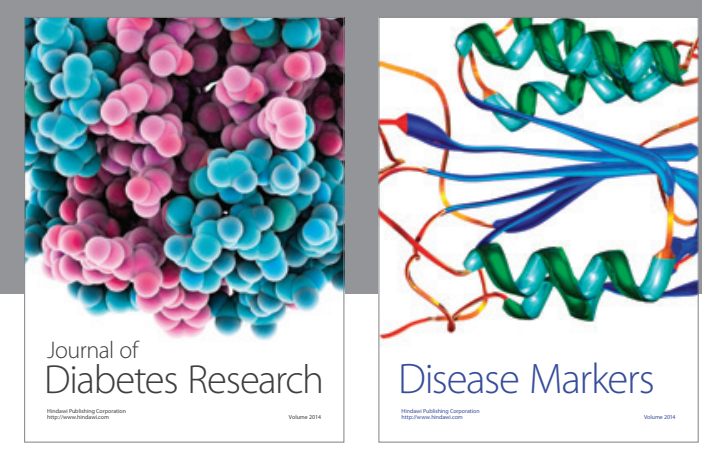

Disease Markers
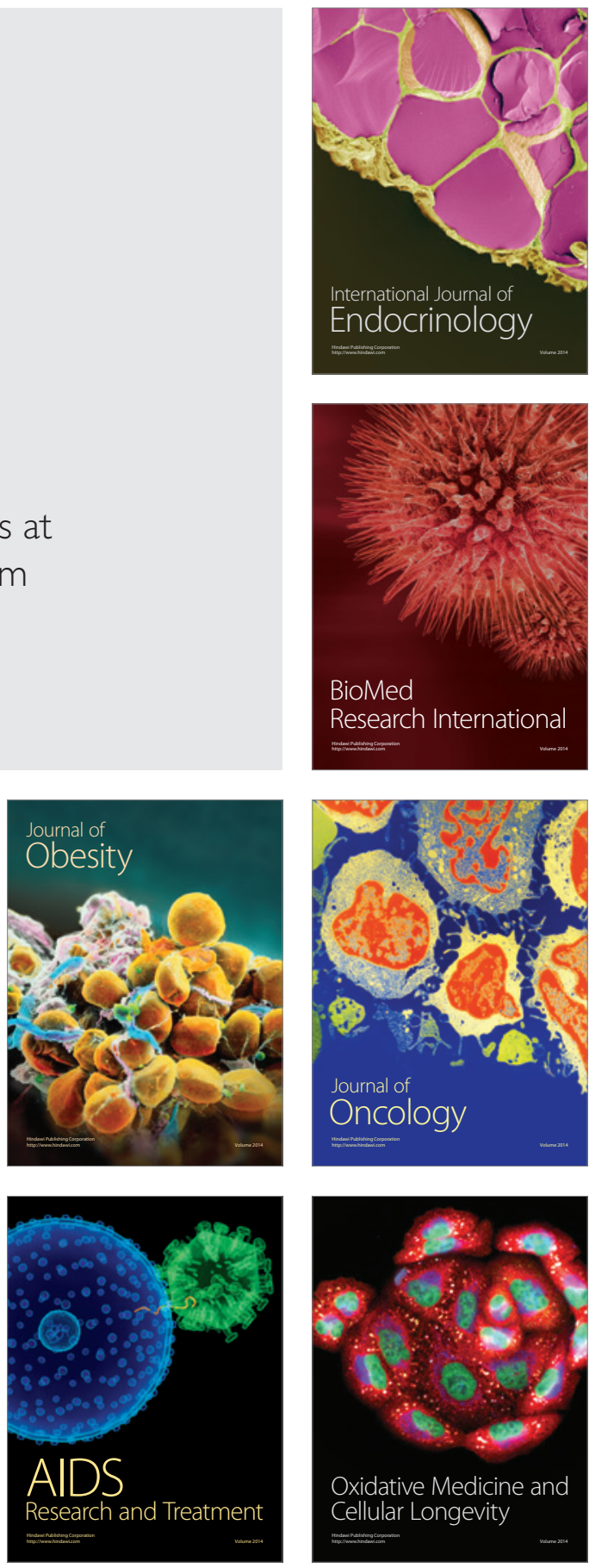